This article is licensed under the Creative Commons Attribution-NonCommercialNoDerivatives 4.0 International License (CC BY-NC-ND) (http://www.karger.com/Services/OpenAccessLicense). Usage and distribution for commercial purposes as well as any distribution of modified material requires written permission.

\title{
Early Initiation of Hemodialysis for Progressive Lactic Acidosis in a Diabetic Patient
}

\author{
Keisuke Nyunoya Naoki Hayase Kent Doi Toshifumi Asada \\ Yoshihiro Ueda Yoichi Kitsuta Naoto Morimura
}

Department of Acute Medicine, The University of Tokyo, Tokyo, Japan

\section{Keywords}

Metformin · Lactic acidosis · Continuous hemodialysis · Intermittent hemodialysis

\begin{abstract}
Metformin, a widely used medicine for diabetes mellitus, is well known to cause lactic acidosis, which may require intensive care, including hemodialysis, especially in severe cases because of the high mortality rate. Because metformin is effectively removed by renal replacement therapy, early initiation of hemodialysis is crucial for metformin overdose. We report a case of a 38-year-old male who was brought to our emergency department (ED) with altered mental status. He subsequently developed severe lactic acidosis with a peak lactate level of 33.4 $\mathrm{mmol} / \mathrm{L}$. No clear etiology was identified for these critical conditions at the ED. Although metformin intoxication could not be confirmed at this time, we decided to start hemodialysis immediately. Soon after hemodialysis, blood $\mathrm{pH}$ and lactate levels dramatically improved. The patient fully recovered after 9 days of intensive care unit (ICU) stay. Later on, his serum metformin concentration was revealed to be $146 \mu \mathrm{g} / \mathrm{mL}$ and $26 \mu \mathrm{g} / \mathrm{mL}$ at ICU admission and after dialysis at day 3 , respectively (therapeutic range, $1-2 \mu \mathrm{g} / \mathrm{mL}$ ). Early initiation of hemodialysis might be beneficial for diabetic patients with unexplained severe lactic acidosis despite uncertainties in history of overdose or serum concentration of metformin.
\end{abstract}




\section{Introduction}

Although metformin is a widely used antidiabetic agent, metformin-associated lactic acidosis (MALA) is one serious complication with a high mortality rate of approximately $30 \%-$ $50 \%[1,2]$. MALA can occur in the setting of therapeutic use and during acute overdose. Compared with chronic toxicity, acute overdose reportedly has higher mortality [1, 2]. Diagnosis of metformin overdose is difficult because of unreliable information and nonspecific symptoms such as tachycardia, hypotension, tachypnea, and altered mental status [3]. In addition, metformin concentration is not routinely measured in the clinical setting. We report a case of a diabetic patient with severe lactic acidosis. Of note, no information on metformin overdose was available upon arrival at the emergency department (ED).

\section{Case Report}

A 38-year-old man was brought to our ED $3 \mathrm{~h}$ after ingestion of drugs for suicide attempt. Only empty packages of $5 \mathrm{mg}$ nitrazepam ( 28 tablets) and $5 \mathrm{mg}$ zolpidem tartrate (13 tablets) were found on the scene. He had schizophrenia and diabetes mellitus. On arrival, his consciousness level was E3V4M6 on the Glasgow Coma Scale. Blood pressure was 94/41 mm Hg, heart rate was $98 / \mathrm{min}$, oxygen saturation was $95 \%$ at room air, body temperature was $36.8^{\circ} \mathrm{C}$, and his pupils were normal in size. Initial venous blood gas showed severe acidemia: $\mathrm{pH} 7.165$, partial pressure of carbon dioxide $43.0 \mathrm{~mm} \mathrm{Hg}$, bicarbonate $14.9 \mathrm{mmol} / \mathrm{L}$, lactate 13.7 $\mathrm{mmol} / \mathrm{L}$, and glucose $85 \mathrm{mg} / \mathrm{dL}$. Laboratory data showed the following: sodium $140 \mathrm{mEq} / \mathrm{L}$, potassium $4.7 \mathrm{mEq} / \mathrm{L}$, chloride $99 \mathrm{mEq} / \mathrm{L}$, calcium $9.5 \mathrm{mg} / \mathrm{dL}$, blood urea nitrogen $8.5 \mathrm{mg} / \mathrm{dL}$, and creatinine $1.38 \mathrm{mg} / \mathrm{dL}$. Drug screening test of urine sample was positive only for benzodiazepine. Electrocardiogram and cranial computed tomography scan showed no remarkable findings. Gastrointestinal decontamination was not indicated because of delayed presentation.

One hour after arrival, his arterial blood gas showed further elevation of lactate to 19.0 $\mathrm{mmol} / \mathrm{L}$ and severe hypoglycemia at $4 \mathrm{mg} / \mathrm{dL}$. At this point, metformin intoxication was suspected based on progressive lactic acidosis without hypoxemia and his past intake of metformin for diabetes mellitus. After endotracheal intubation and bolus administration of glucose and sodium bicarbonate, he was admitted to the intensive care unit (ICU) and continuous hemodialysis (CHD) was immediately started with blood flow rate (Qb) of $100 \mathrm{~mL} / \mathrm{min}$ and dialysate flow rate (Qd) of 6,000 mL/h. Although he had a nadir $\mathrm{pH}$ of 7.079 and peak lactate level of $33.4 \mathrm{mmol} / \mathrm{L}$, his acidosis stabilized $6 \mathrm{~h}$ after CHD initiation. Because his hemodynamic status became stable on day 2, intermittent hemodialysis (IHD) was conducted for $6 \mathrm{~h}$ (Qb 200 $\mathrm{mL} / \mathrm{min}$ and $\mathrm{Qd} 30,000 \mathrm{~mL} / \mathrm{h}$ ). Both blood $\mathrm{pH}$ and lactate level showed dramatic improvement after IHD (Fig. 1). After one IHD session, CHD was conducted until day 3 in case of resurgence of MALA [4]. The patient was extubated on day 5 and was transferred to the psychiatric unit without any other sequelae on day 9. On hindsight, serum metformin level was found to be $146 \mu \mathrm{g} / \mathrm{mL}$ upon ICU admission (normal therapeutic range, 1-2 $\mu \mathrm{g} / \mathrm{mL}$ ) [5, 6], confirming the diagnosis of acute metformin intoxication. 


\section{Discussion}

MALA is generally treated with supportive therapy, including renal replacement therapy (RRT) [2, 3]. RRT is recommended because metformin is a small molecule (165 Da) with limited protein binding. The advantages of RRT are not only metformin removal, but also improvement of lactate level and correction of blood $\mathrm{pH}[1-3,7]$. IHD has been preferred over CHD with regard to the efficacy of metformin removal. On the other hand, one report showed no difference in the rate of metformin removal between IHD and high-flow CHD (Qd 5,000 $\mathrm{mL} / \mathrm{h}$ for $8 \mathrm{~h}$ ) in patients with MALA [7]. In the present case, CHD (Qd 6,000 mL/h) was conducted before IHD because of hemodynamic instability. Moreover, we decided to initiate hemodialysis early in order to achieve a favorable outcome. Indeed, a previous report suggested that delayed initiation decreased the beneficial impacts of hemodialysis [1].

The mortality rate of metformin overdose had been unacceptably high. Reportedly, intentional overdose with nadir blood pH of less than 6.9 or peak lactate level of greater than 25 $\mathrm{mmol} / \mathrm{L}$ increased mortality to as high as $83 \%$. The mortality of patients with peak metformin concentration greater than $50 \mu \mathrm{g} / \mathrm{mL}$ was shown to be $38 \%$ [5]. In our case, although a lactate level of $33.4 \mathrm{mmol} / \mathrm{L}$ and a metformin concentration of $146 \mu \mathrm{g} / \mathrm{mL}$ were higher than these reported values, the patient recovered without any serious sequelae. Severe hypoglycemia was observed in this case. However, metformin had been rarely associated with severe hypoglycemia because it does not directly stimulate insulin secretion. In fact, the hypoglycemic risk of metformin was reported to range from only 0 to $21 \%$ [8].

In summary, immediate hemodialysis in a diabetic patient, even without confirmation of metformin overdose, successfully improved severe lactic acidosis. This case suggested that early initiation of hemodialysis should be considered for diabetic patients with progressive severe lactic acidosis.

\section{Statement of Ethics}

The authors have no ethical conflicts to disclose. The University of Tokyo Institutional Review Board approved this study with permission of a waiver of consent by patients (\#3820).

\section{Disclosure Statement}

The authors have no conflicts of interest to declare.

\section{Funding Sources}

This research did not receive any specific grant from funding agencies in the public, commercial, or not-for profit sectors. 


\section{Author Contributions}

K.N., N.H., K.D., T.A., and Y.U. were responsible for this case treatment. Y.K. and N.M. contributed as supervisors. K.N., N.H., and K.D. drafted the manuscript. All authors read and approved the final manuscript.

\section{References}

1 Calello DP, Liu KD, Wiegand TJ, Roberts DM, Lavergne V, Gosselin S, et al.; Extracorporeal Treatments in Poisoning Workgroup. Extracorporeal treatment for metformin poisoning: systematic review and recommendations from the extracorporeal treatments in poisoning workgroup. Crit Care Med. 2015 Aug;43(8):1716-30.

2 Peters N, Jay N, Barraud D, Cravoisy A, Nace L, Bollaert PE, et al. Metformin-associated lactic acidosis in an intensive care unit. Crit Care. 2008;12(6):R149.

3 Spiller HA, Sawyer TS. Toxicology of oral antidiabetic medications. Am J Health Syst Pharm. 2006 May;63(10):929-38.

4 Akoglu H, Akan B, Piskinpasa S, Karaca O, Dede F, Erdem D, et al. Metformin-associated lactic acidosis treated with prolonged hemodialysis. Am J Emerg Med. 2011 Jun;29(5):575.e3-5.

5 Dell'Aglio DM, Perino LJ, Kazzi Z, Abramson J, Schwartz MD, Morgan BW. Acute metformin overdose: examining serum $\mathrm{pH}$, lactate level, and metformin concentrations in survivors versus nonsurvivors: a systematic review of the literature. Ann Emerg Med. 2009 Dec;54(6):818-23.

6 Kazory A, Walsh K, Harman E, Talor Z. Is metformin safe in patients with mild renal insufficiency? Diabetes Care. 2007 Feb;30(2):444.

7 Nguyen HL, Concepcion L. Metformin intoxication requiring dialysis. Hemodial Int. 2011 Oct;15 Suppl 1:S6871.

8 Bolen S, Feldman L, Vassy J, Wilson L, Yeh HC, Marinopoulos S, et al. Systematic review: comparative effectiveness and safety of oral medications for type 2 diabetes mellitus. Ann Intern Med. 2007 Sep;147(6):386-99.

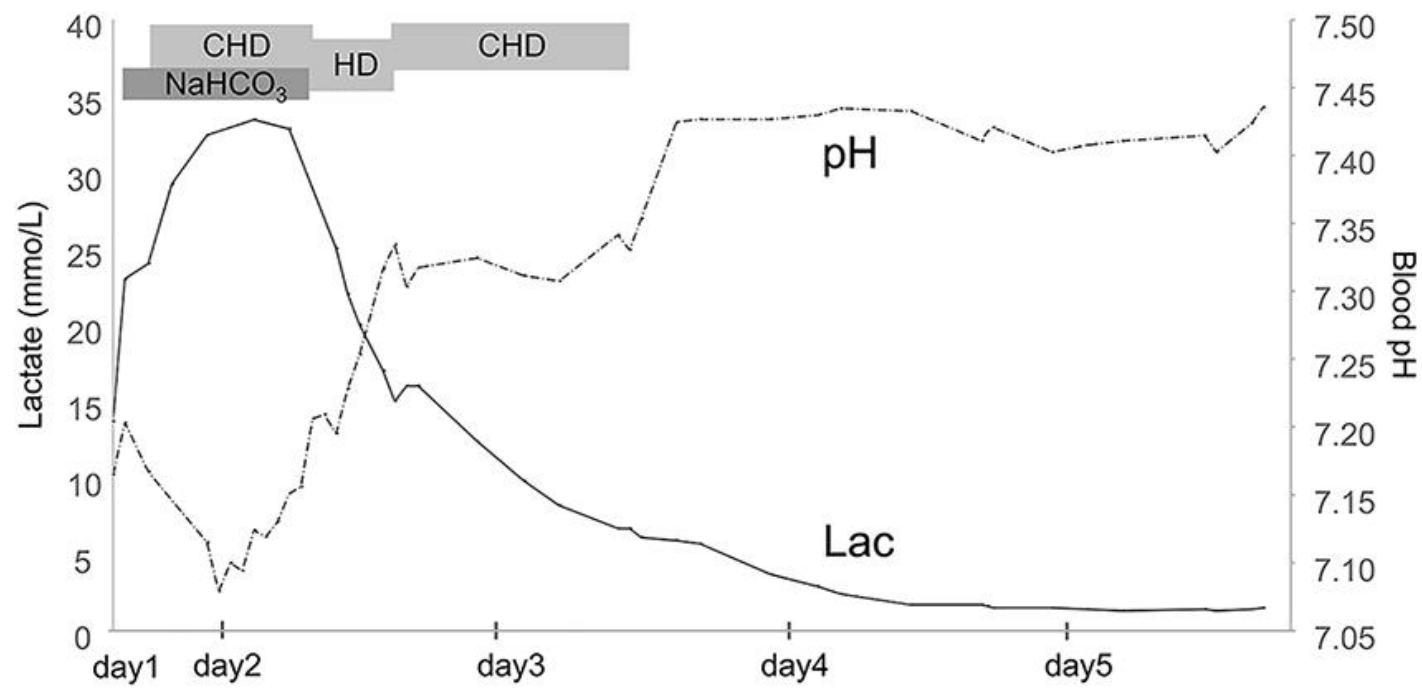

Fig. 1. Clinical course of metformin-associated lactic acidosis. Blood $\mathrm{pH}$ and lactate level improved after initiation of hemodialysis. CHD, continuous hemodialysis; HD, hemodialysis. 